\title{
Further evidence against the role renal medullary perfusion in short-term control of arterial pressure in normotensive and mildly or overtly hypertensive rats
}

\author{
Bożena Bądzyńska ${ }^{1}$ (1) - Iwona Baranowska ${ }^{1}$ - Janusz Sadowski ${ }^{1}$ \\ Received: 3 December 2020 / Revised: 1 February 2021 / Accepted: 3 February 2021 / Published online: 2 March 2021 \\ (C) The Author(s) 2021
}

\begin{abstract}
Earlier evidence from studies of rat hypertension models undermines the widespread view that the rate of renal medullary blood flow (MBF) is critical in control of arterial pressure (MAP). Here, we examined the role of MBF in rats that were normotensive, with modest short-lasting pressure elevation, or with overt established hypertension. The groups studied were anaesthetised Sprague-Dawley rats: (1) normotensive, (2) with acute i.v. norepinephrine-induced MAP elevation, and (3) with hypertension induced by unilateral nephrectomy followed by administration of deoxycorticosterone-acetate (DOCA) and $1 \% \mathrm{NaCl}$ drinking fluid for 3 weeks. MBF was measured (laser-Doppler probe) and selectively increased using 4-h renal medullary infusion of bradykinin. MAP, renal excretion parameters and post-experiment medullary tissue osmolality and sodium concentration were determined. In the three experimental groups, baseline MAP was 117, 151 and $171 \mathrm{mmHg}$, respectively. Intramedullary bradykinin increased MBF by $45 \%, 65 \%$ and $70 \%$, respectively, but this was not associated with a change in MAP. In normotensive rats a significant decrease in medullary tissue sodium was seen. The intramedullary bradykinin specifically increased renal excretion of water, sodium and total solutes in norepinephrine-treated rats but not in the two other groups. As previously shown in models of rat hypertension, in the normotensive rats and those with acute mild pressure elevation (resembling labile borderline human hypertension), 4-h renal medullary hyperperfusion failed to decrease MAP. Nor did it decrease in DOCA-salt model mimicking low-renin human hypertension. Evidently, within the 4-h observation, medullary perfusion was not a critical determinant of MAP in normotensive and hypertensive rats.
\end{abstract}

Keywords Arterial blood pressure · Arterial hypertension · DOCA-salt hypertension · Norepinephrine $\cdot$ Renal medullary circulation

\section{Introduction}

Despite a substantial progress in the treatment of arterial hypertension over the past three decades, the effectiveness of the available therapeutic measures, including the novel approach based on catheter-based renal denervation $[3,30]$, is still limited and cannot be regarded as satisfactory. Multiple forms of human primary hypertension have been identified, with a variety of pathogenetic mechanisms underlying or

Bożena Bądzyńska

bbadzynska@imdik.pan.pl

1 Department of Renal and Body Fluid Physiology, Mossakowski Medical Research Institute, Polish Academy of Sciences, 5 Pawińskiego St., 02-106 Warsaw, Poland contributing to the development of the final phenomenon, i.e. an increase in systemic vascular resistance. As reviewed recently [28], the pathogenesis of hypertension is still a matter of debate, mostly between the proponents of "renocentric" theory rooted in the seminal work of Guyton and his adherents $[13,22,23]$ and the researchers who propose that the origin of the phenomena leading to hypertension is in the brain and the nervous system in general ("neurocentric" theory), with a special role ascribed to activity of the sympathetic nervous system, at its different levels $[17,21,24,27]$. Over the past decade, the very basic principles of the renocentric concept have been ardently criticised $[2,5,6,27,32]$. Therefore, attempts are made to reconcile the opposed views and incorporate the well-documented elements of the neurocentric and renocentric theories to develop an integrative concept $[8,9,18,19]$. 
Within the renocentric concept, the postulated crucial events in the mechanisms which correct elevation of BP include an increase in (allegedly poorly autoregulated) medullary blood flow (MBF) leading to increased renal interstitial hydrostatic pressure, first within the medulla and then throughout the kidney (including the proximal peritubular space), followed by a change in Starling forces and inhibition of tubular transport and the development of natriuresis. Considering the effect per se of increasing vasa recta blood flow, an additional mechanism for inhibition of tubular transport could be the phenomenon of wash-out of solutes from the medullary interstitium and reduction the medullary/papillary osmotic hypertonicity, leading to inhibition of fluid reabsorption along the medullary tubule segments [7, 14, 15, 25]. However, substantial evidence from animal experiments, as reviewed recently [28] and also a recent report from a patient study [1], contradict the causal role of MBF in the process.

In an earlier study with three variants of rat hypertension [11], we showed that experimental elevation of MBF had no rapid effect on BP, excluding thereby a possible role of medullary vasodilator (medullipin) allegedly released within less than $1 \mathrm{~h}$ after MBF elevation, as postulated by Muirhead [26]. More recently, we showed that also longer lasting $(4 \mathrm{~h})$ medullary hyperperfusion failed to decrease BP in three models of rat hypertension [10].

In the present work, we first tested the hypothesis that elevation of medullary perfusion using intramedullary infusion of bradykinin (Bk) would lower arterial pressure in normotensive Sprague-Dawley rats (group: S-D) within a time interval $(4 \mathrm{~h})$ that would not be compatible with natriuresis and extracellular volume contraction as a causal factor. Normotensive rats were not studied in our earlier work [10] so such investigation was needed, given that the rate of medullary perfusion has long been proposed to be involved in hour-to-hour maintenance of normal arterial pressure [13, 22]. We also thought it important to compare the results in normotensive rats with those in the rats of the same strain with acute modest elevation of blood pressure obtained with NE infusion (group S-D+NE). The purpose was to examine the effect of pressure elevation per se, hopefully without mobilizing secondary pathogenetic mechanisms which, in the long run, would actually result in creation of a complex model of arterial hypertension. We assumed this approach would provide a situation which resembles transient elevations of arterial pressure observed in patients with labile or borderline hypertension.

In the next step, we wished to examine the effect of medullary hyperperfusion in established hypertension, a DOCAsalt (deoxycorticosterone plus $1 \% \mathrm{NaCl}$ drinking) model, a variant of salt-dependent hypertension yet one with pronounced neurogenic pathogenetic component. This model has not been explored in our earlier studies of the role of renal medullary perfusion in BP control. It is emphasized that, given the limited duration of experimental medullary hyperperfusion, the results of this study pertain to hour-to-hour control of arterial pressure. Obviously, such control is unrelated to the mechanism dependent on natriuresis sustained over days and followed by extracellular fluid volume contraction.

\section{Material and Methods}

Ethical approval The experimental procedures were approved by the extramural Second Local Ethical Committee for Animal Experimentation, Warsaw.

Male Sprague-Dawley (S-D) rats were derived from the animal house of the Mossakowski Medical Research Institute, Polish Academy of Sciences. Experiments were designed to examine whether in normotensive or hypertensive rats a selective increase in renal medullary perfusion (MBF) induced by intramedullary infusion of bradykinin (Bk) would lower mean arterial blood pressure (MAP), medullary tissue osmolality, and sodium concentration, and if it affects renal excretion.

Acute experiments were performed with male anaesthetised S-D rats, aged 12 weeks, weighing 280-340 g, maintained on standard sodium diet $\left(0.25 \% \mathrm{Na}^{+} \mathrm{w} / \mathrm{w}\right.$, SSNIFF, GmbH, Soest, Germany), with free access to water. The groups studied were as follows: (1) normotensive S-D rats, Bk: $n=8$, solvent: $n=6$; (2) S-D rats given intravenous norepinephrine infusion to elevate baseline MAP to about 150 mmHg (S-D+NE, Bk: $n=7$, solvent: $n=8$ ); (3) S-D rats with hypertension induced by initial uninephrectomy followed by replacing drinking water with $0.9 \% \mathrm{NaCl}$ and application of deoxycorticosterone acetate (DOCA, $50 \mathrm{mg}$ pellet implanted subcutaneously, the contents released over 21 days, Bk: $n=7$, solvent: $n=7$ ). Experiments were performed 21 days after the implantation (DOCA-salt model).

\section{Surgical preparations}

All experiments were performed in uninephrectomized rats. In S-D normotensive rats and S-D+NE rats, right-side nephrectomy was performed at the start of the acute experiment. DOCA-salt rats were subjected to right-side nephrectomy under inhalation anaesthesia (4\% isoflurane/oxygen mixture) 2 weeks before acute experiment. Early nephrectomy is needed to effectively increase blood pressure in this hypertension model. Metacam $\left(0.4 \mathrm{mg} \mathrm{kg}^{-1} \mathrm{BW}\right.$, Boehringer, Ingelheim, Germany) and baytril (10 mg kg${ }^{-1} \mathrm{BW}$, Bayer, Leverkusen, Germany) were given subcutaneously for analgesia and to prevent infection, respectively. Nephrectomy was performed from a flank incision, and care was taken to leave the right adrenal gland intact. 
In acute experiments, the rats were anaesthetised with thiopental (Sandoz GmbH, Kundl, Austria), $100 \mathrm{mg} \mathrm{kg}^{-1}$ i.p., which provided stable anaesthesia for at least $5 \mathrm{~h}$, with additional small subcutanaeous doses when needed. The jugular vein was cannulated for infusion of fluids and drugs. A polyethylene tube was placed in the trachea to ensure free airways. Body temperature was maintained at about $37^{\circ} \mathrm{C}$ by means of a servo-controlled heating pad. During surgery, to maintain plasma volume, fluid losses were compensated by intravenous infusion of 3\% bovine albumin in Ringer's solution at $2.5 \mathrm{ml} /$ $\mathrm{h}$. With surgery completed within about $30 \mathrm{~min}$, this infusion was replaced by $0.9 \% \mathrm{NaCl}$, with addition of norepinephrine (NE) in the appropriate group, given at the same volume infusion rate of $2.5 \mathrm{ml} / \mathrm{h}$. For measurement of mean arterial blood pressure (MAP), a Teflon catheter was introduced into the right femoral artery and connected with a Stoelting blood pressure meter (Stoelting, Wood Dale IL, USA).

The left kidney was exposed from a subcostal flank incision and immobilized in a lucite cup, and the ureter was cannulated for timed urine collection to measure urine flow $(\mathrm{V})$, sodium excretion $\left(\mathrm{U}_{\mathrm{Na}} \mathrm{V}\right)$, and total solute excretion $\left(\mathrm{U}_{\mathrm{osm}} \mathrm{V}\right)$. To measure total renal blood flow (RBF), a Transonic cuff probe was placed on the renal artery and connected with a Transonic flowmeter (Type T106, Transonic System Inc. Ithaca, NY, USA). Blood perfusion of the renal medulla (MBF) was measured as laser-Doppler flux using Periflux 4001 system (Perimed, Jarfalla, Sweden). A 32-gauge stainless steel cannula, connected with an infusion pump, was inserted into the kidney, with the tip located at the outerinner medullary border.

\section{Protocols}

In each protocol, an intramedullary infusion of $0.9 \% \mathrm{NaCl}$ bradykinin (Bk) solvent was started at a volume rate of $0.5 \mathrm{ml} \mathrm{h}^{-1}$, followed by Bk infusion in experimental periods.

In S-D+NE rats, norepinephrine was infused to the jugular vein (at $0.83 \mathrm{mg} \mathrm{h}^{-1} \mathrm{~kg}^{-1} \mathrm{BW}$, i.v.) starting immediately after surgery and continued until the end of the experiment. In a preliminary group $(n=6)$, the effect of NE on blood pressure, renal haemodynamics and renal excretory function was first determined, without later application of Bk.

With the surgery completed, $1 \mathrm{~h}$ was allowed for equilibration of the haemodynamic parameters and urine excretion, followed by a 30-min control measurement period and urine collection. Subsequently, intramedullary solvent infusion was replaced by Bk (Sigma-Aldrich, Basel, Switzerland) solution given at $0.27 \mathrm{mg} \mathrm{h}^{-1} \mathrm{~kg}^{-1} \mathrm{BW}$ during $4 \mathrm{~h}$. Ten minutes later, MAP, RBF and MBF recording was started and continued throughout the experiment, along with 30 -min urine collections.

In parallel time-control experiments, Bk solvent was infused throughout the experiment, with measurements performed as usual. At the end of all experiments, the left kidney was removed and the inner renal medulla was excised for measurement of tissue osmolality and sodium concentration $\left[\mathrm{Na}^{+}\right]$. The rats were killed with an overdose of thiopental.

\section{Determination of osmolality and sodium concentration $\left(\left[\mathrm{Na}^{+}\right]\right)$in renal inner medulla}

After the experiment, the kidney was excised, sectioned along the sagittal paracentral plane in a way to preserve the inner (white) medulla intact. To obtain from the excised white medulla a standard medullary piece, the tissue was punched out using a stainless steel tube slightly oval at the cross section. The pieces included most of the white medulla but not the tip region of the papilla. They were weighed and subjected to 1-h extraction in a 1-ml volume of boiling distilled water and osmolality and sodium concentration of the extraction fluid (equilibrated with tissue fluid) was determined. The final results were expressed as mosmol and milimol $\mathrm{Na}$ per $\mathrm{kg}$ of wet medullary tissue [16].

\section{Analytical methods}

Urine volume was determined gravimetrically. Urine and tissue osmolality were measured using a cryoscopic osmometer (Osmomat 030, Gonotec GmbH, Berlin, Germany). Urine and tissue sodium concentrations were determined using the flame photometer (Jenway PFP7, Essex, UK).

\section{Statistics}

Data are expressed as means \pm SEM. Significance of changes within one group over time was first evaluated by repeated measures analysis of variance (ANOVA), followed by modified Student $t$ test for dependent variables, using Bonferroni correction for multiple comparisons [31]. Differences between profiles for bradykinin and solvent infusion were first analyzed by the repeated measurements multivariable ANOVA, followed by Duncan's test (STATISTICA 10.0, StatSoft Polska Inc.). $P \leq 0.05$ was taken to indicate significance of differences.

\section{Results}

Baseline values of the mean arterial pressure (MAP) and renal haemodynamic and excretion parameters in normotensive S$\mathrm{D}$ rats, in S-D + NE group and in DOCA-salt hypertensive rats are presented in Table 1 . The data present the values for the left kidney since all the rats had undergone contralateral nephrectomy: the S-D and S-D+NE groups at the start of an acute experiment and the DOCA-salt rats 2 weeks earlier. Since in the latter group a substantial left kidney hypertrophy 
Table 1 Baseline values of mean arterial pressure, renal haemodynamics and renal excretion parameters and kidney weight (KW) in S-D normotensive rats, in norepinephrine-induced blood pressure elevation and in DOCA-salt hypertensive rats

\begin{tabular}{|c|c|c|c|c|c|c|c|}
\hline & MAP & $\mathrm{RBF}$ & MBF & V & $\mathrm{U}_{\mathrm{Na}} \mathrm{V}$ & $\mathrm{U}_{\mathrm{osm}} \mathrm{V}$ & KW \\
\hline$n$ & $\mathrm{mmHg}$ & 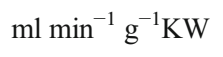 & $\mathrm{PU}$ & $\mu \mathrm{l} \min ^{-1} \mathrm{~g}^{-1} \mathrm{KW}$ & $\mu \mathrm{mol} \min ^{-1} \mathrm{~g}^{-1} \mathrm{KW}$ & $\mu \mathrm{osm} \min ^{-1} \mathrm{~g}^{-1} \mathrm{KW}$ & $\mathrm{g}$ \\
\hline S-D (14) & $117 \pm 1$ & $7.7 \pm 0.5$ & $137 \pm 16$ & $3.9 \pm 0.4$ & $0.4 \pm 0.04$ & $5.4 \pm 0.4$ & $1.41 \pm 0.05$ \\
\hline S-D+NE (15) & $151 \pm 2$ & $6.1 \pm 0.3$ & $115 \pm 10$ & $22.6 \pm 6.3$ & $0.7 \pm 0.2$ & $8.6 \pm 0.9$ & $1.34 \pm 0.03$ \\
\hline DOCA-salt (14) & $171 \pm 4$ & $4.5 \pm 0.7$ & $93 \pm 10$ & $13.8 \pm 2.9$ & $1.5 \pm 0.3$ & $6.8 \pm 1.0$ & $3.14 \pm 0.08$ \\
\hline
\end{tabular}

MAP mean arterial pressure, RBF renal blood flow, MBF renal medullary perfusion, excretion of water $(V)$, sodium $\left(U_{\mathrm{Na}} V\right)$ and total solutes $\left(\mathrm{U}_{\mathrm{osm}} \mathrm{V}\right)$. Pooled control data from Bk and solvent infusion studies, $\mathrm{n}$ values are given in parentheses. Groups: normotensive Sprague-Dawley (S-D) rats; norepinephrine-induced hypertension (S-D+NE); DOCA-salt hypertensive rats.

was seen, the renal blood flow, $\mathrm{V}, \mathrm{U}_{\mathrm{Na}} \mathrm{V}$ and $\mathrm{U}_{\text {osm }} \mathrm{V}$ values are expressed per gram kidney weight $(\mathrm{KW})$.

It is seen that, on the average, NE infusion induced an acute elevation of BP by $34 \mathrm{mmHg}(+29 \%)$ whereas in DOCA-salt hypertension model, the pressure was $54 \mathrm{mmHg}$ above the level for control S-D rats $(+46 \%)$. By contrast, RBF and MBF showed an inverse (decreasing) trend pattern in the respective groups. Therefore, in SD+NE and DOCA-salt rats, the renal vascular resistance can be estimated to be, respectively, about 1.6-fold and 2.6-fold higher than in S-D normotensive rats.

Normotensive rats Effects of intramedullary Bk or solvent infusions on MAP, renal haemodynamic and renal excretion parameters in normotensive S-D rats are presented in

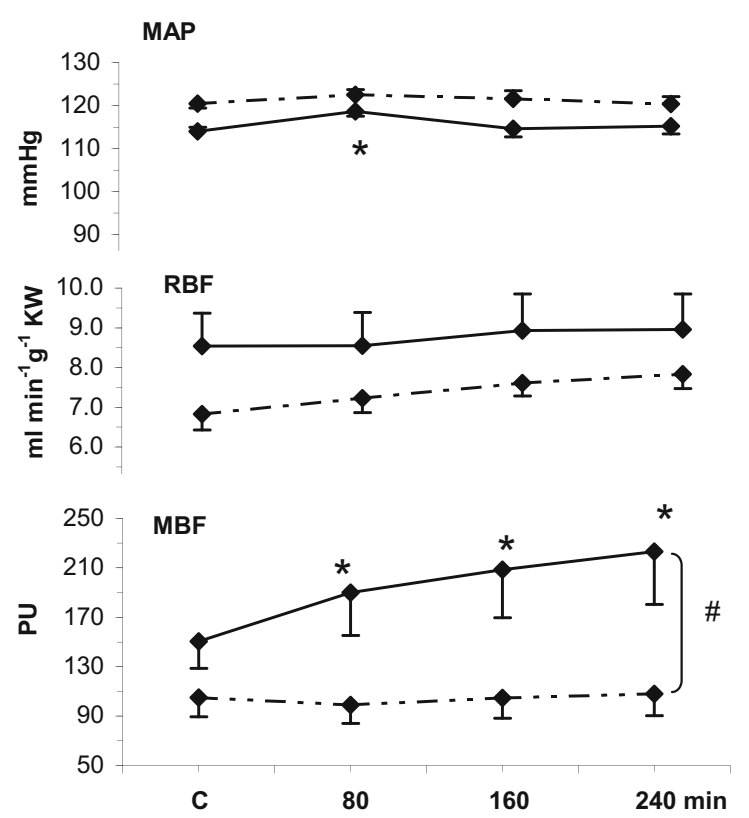

Fig. 1 Responses of mean arterial blood pressure, renal haemodynamics and excretion parameters to $4-\mathrm{h}$ renal intramedullary infusion of bradykinin (Bk) or solvent in normotensive rats. MAP, mean arterial pressure; RBF, renal blood flow; MBF, renal medullary perfusion; excretion of water $(\mathrm{V})$, sodium $\left(\mathrm{U}_{\mathrm{Na}} \mathrm{V}\right)$ and total solutes $\left(\mathrm{U}_{\mathrm{osm}} \mathrm{V}\right)$. Means \pm SEM: averaged 30-min values measured in the control period
Fig. 1. To assess if Bk effectively increased medullary perfusion (MBF), as intended, the profile of the induced change over time was compared to that in time-control experiments (solvent infusion) using multivariable repeated measurement ANOVA (Table 2). It is seen that a highly significant MBF increase (demonstrable also relative to the profile for the solvent) was observed. A major $(+45 \%)$ Bk-induced increase in MBF was selective, i.e. not associated with any significant change in $\mathrm{RBF}$, and was not associated with any significant change in MAP which remained stable over four hours. All parameters of renal excretion increased progressively and significantly. For $\mathrm{V}$ and $\mathrm{U}_{\mathrm{Na}} \mathrm{V}$ (but not $\mathrm{U}_{\mathrm{osm}} \mathrm{V}$ ) the increase only tended to be greater with Bk compared to solvent infusion.
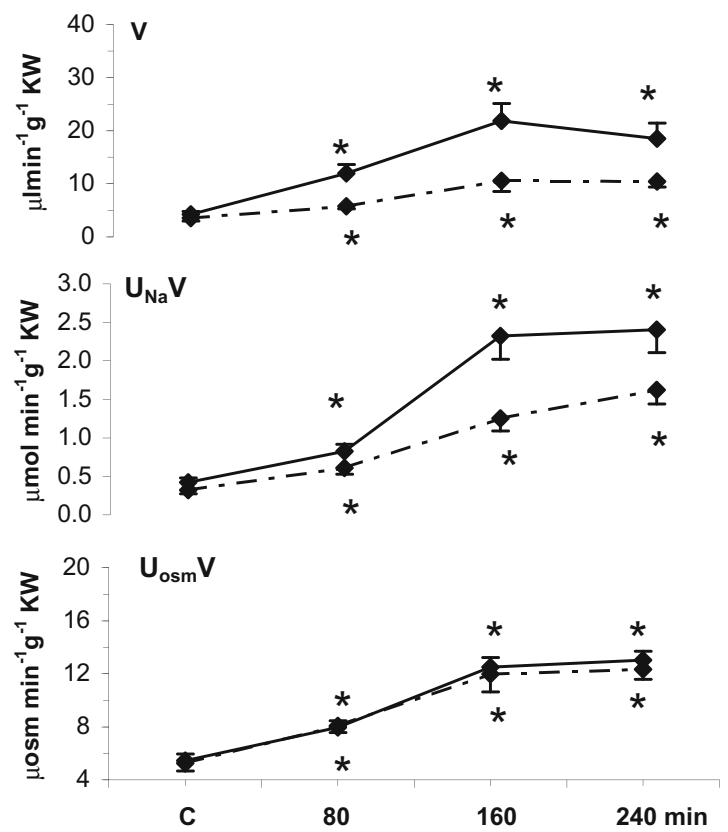

(C) and at the end of 80,160 and 240 min of Bk infusion. Bk, continued line $(n=8)$; solvent, dotted line $(n=6)$. \#Significant difference between profiles at $P<0.004$ (repeated measurement ANOVA); * significantly different from pre-infusion control at $P<0.05$ or less (Duncan's post hoc test) 
Table 2 Statistical comparison of the change in medullary perfusion (MBF) during 4 hof bradykinin versus solvent infusion into the renal medulla in the three experimental groups

\begin{tabular}{lllll}
\hline Group & SS & MS & $F$ & $P<$ \\
\hline S-D (7, 6) & 9054 & 3018 & 5.3824 & 0.0040 \\
S-D+NE (7, 8) & 13751 & 4583 & 6.9015 & 0.0010 \\
DOCA-salt (7, 7) & 12967 & 4322 & 4.1004 & 0.0133 \\
\hline
\end{tabular}

Comparison made using repeated measures multivariate ANOVA (post hoc Duncan's test). S-D, normotensive Sprague-Dawley rats; S-D+NE, norepinephrine-induced hypertensive rats; DOCA-salt, hypertensive rats (n values for bradykinin, solvent). SS, sum of squares, MS, mean square, $\mathrm{F}$ value. The degree of freedom for interaction of time $(\mathrm{t}) \times$ treatment $(\mathrm{k})$ factor equals $(n-t)(n-k)$, i.e. $(4-1)(2-1)=3$ for each group

Acutely hypertensive rats The study of S-D+NE rat group was preceded by examination in six rats of the feasibility of NE infusion as a tool for acute and possibly sustained elevation of MAP. Within 40-min infusion MAP stabilized at a level $23 \%$ above the control, which was associated with a significant $7 \%$ decrease in RBF (Fig. 2). The calculated renal vascular resistance increased from $19.2 \pm 1.3$ to $25.1 \pm 1.8 \mathrm{mmHg}$ $\mathrm{ml}^{-1} \min (+30 \%)$. MBF decreased more $(-23 \%)$ than did RBF.

In the main study of rats with NE-induced elevation of MAP (Fig. 3) intramedullary Bk increased MBF by $65 \%$ while with solvent infusion no significant increase was seen; the difference between the two MBF profiles was highly significant (Table 2). However, with both Bk and the solvent, MAP remained stable throughout the experiment. In Bk- but not in solvent-infused rats, $\mathrm{V}, \mathrm{U}_{\mathrm{Na}} \mathrm{V}$ and UosmV showed a progressive significant increase; the excretion profiles were not parallel to that of MBF.

DOCA-salt rats In rats with DOCA-salt hypertension, as in the two former groups, intramedullary Bk significantly increased

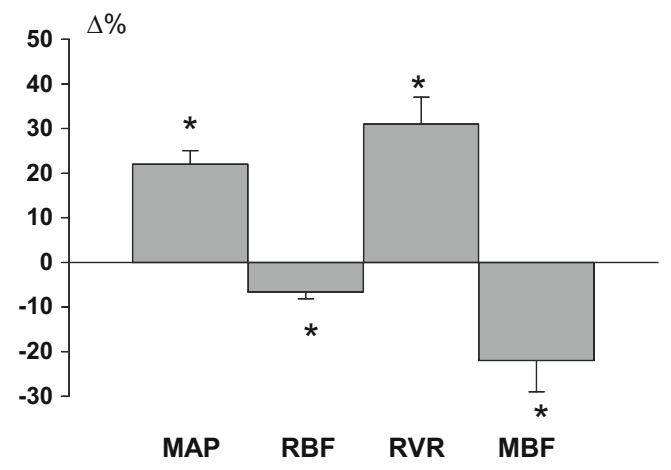

Fig. 2 Effects of intravenous infusion of norepinephrine at $0.83 \mathrm{mg} \mathrm{h}^{-1}$ $\mathrm{kg}^{-1} \mathrm{BW}$ on hemodynamic parameters in normotensive Sprague-Dawley rats $(n=6)$. MAP, mean arterial pressure; RBF, renal blood flow; RVR, renal vascular resistance; $\mathrm{MBF}$, renal medullary perfusion. Mean $\Delta \% \pm$ SEM, *significant change from control at $P<0.05$ or less (paired Student's $t$ test)
MBF (+ 70\%) while with the solvent the change was not significant (Fig. 4, Table 2). Unlike with normotensive and S-D+NE rats, MAP did decrease during experiment but the change tended to be more pronounced with the solvent than with Bk infusion. RBF and the renal excretion parameters did not significantly change with either infusion.

Tissue studies Effects of Bk and solvent infusion on total solute (osmolality) and $\mathrm{Na}^{+}$concentration in the inner medullary tissue are shown in Table 3. It is seen that in each of the three rat groups both the mean osmolality and $\mathrm{Na}^{+}$values appeared to be lower in the tissue of rats infused Bk, as compared with the solvent, but the Bk vs. solvent difference proved significant only for the $\mathrm{Na}^{+}$value in normotensive S$\mathrm{D}$ rats. A significant difference in tissue $\mathrm{Na}^{+}$(but not osmolality) was also seen when the data for the three groups were pooled $(n=22): 124 \pm 8 \mathrm{mmol} \mathrm{kg}^{-1}$ for Bk and $144 \pm 6 \mathrm{mmol}$ $\mathrm{kg}^{-1}$ for the solvent $(p<0.04)$, indicating a modest wash-out of tissue sodium during increased medullary perfusion.

\section{Discussion}

While in the past three decades the main effort in evaluation of the role of MBF in control of BP focused on animal and human hypertension, the rate of medullary perfusion was also proposed to be involved in the regulation of pressure fluctuations under physiological conditions [13, 22].

The first important finding in this study was that in anaesthetised normotensive rats a 4 -h increase in medullary blood flow did not induce any decrease in arterial blood pressure. This was so even though medullary hyperperfusion caused some modest wash-out of inner medullary sodium and renal sodium excretion at least tended to increase. No evidence for a fall in BP despite an almost 50\% increase in MBF maintained during four hours indicates that within this time interval medullary hyperperfusion has no role in control of BP in normotensive animals. This extends our earlier observation on the absence of such hypotensive action of medullary hyperperfusion in three experimental models of rat hypertension [10] to include also physiological blood pressure control. Thus, the finding is not compatible with the long postulated role of medullary circulation changes to correct temporary (hour-to-hour) BP elevation in normotensive animals, e.g. in response to a fluid load [13, 22, 23]. In other words, our present findings put to doubt the hypothesis that in healthy animals an acute elevation of arterial pressure can be corrected within hours via an increase in - allegedly poorly autoregulated-MBF [13, 14, 22, 25]. Such scenario could not be excluded a priori because increasing perfusion of the medulla results in elevation of local interstitial hydrostatic pressure, which is very likely to alter the complex status of local endocrine, paracrine and neural influences (e.g. of 


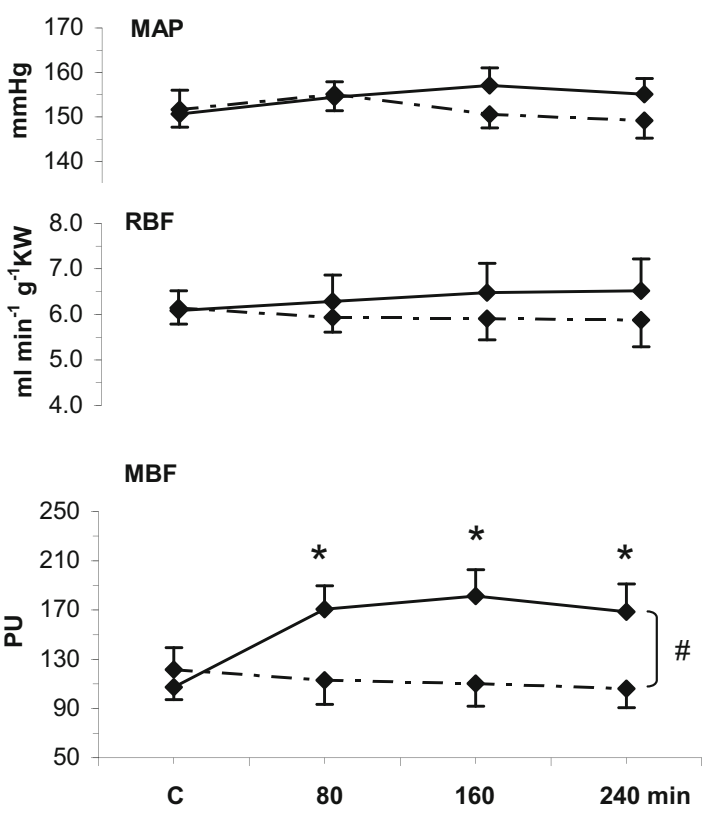

Fig. 3 Responses of mean arterial pressure, renal haemodynamics and excretion parameters to 4-h renal intramedullary infusion of bradykinin (Bk) or solvent in rats with norepinephrine-induced blood pressure elevation MAP, mean arterial pressure; RBF, renal blood flow; MBF, renal medullary perfusion; excretion of water $(\mathrm{V})$, sodium $\left(\mathrm{U}_{\mathrm{Na}} \mathrm{V}\right)$ and total solutes $\left(\mathrm{U}_{\mathrm{osm}} \mathrm{V}\right)$. Means \pm SEM: averaged 30 -min values measured

angiotensin II, endothelin, prostanoids, nitric oxide and reactive oxygen species) [19]. Such changes could within a few

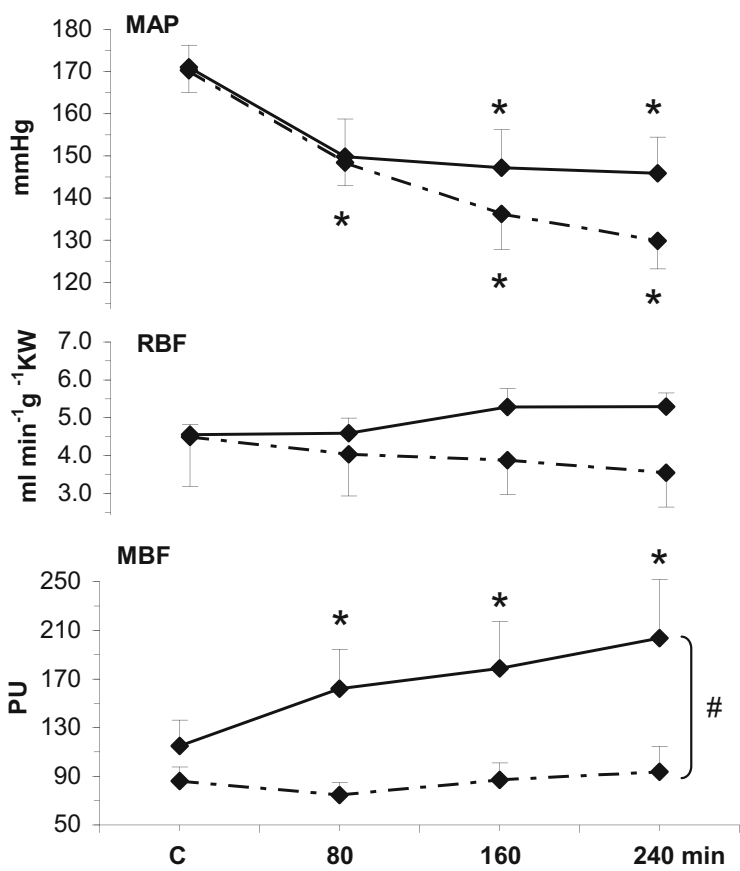

Fig. 4 Responses of mean arterial pressure, renal haemodynamics and excretion parameters to 4-h renal intramedullary infusion of bradykinin (Bk) or solvent in rats with DOCA-salt hypertension model MAP, mean arterial pressure; $\mathrm{RBF}$, renal blood flow; $\mathrm{MBF}$, renal medullary perfusion; excretion of water $(\mathrm{V})$, sodium $(\mathrm{UNaV})$ and total solutes (UosmV). Means \pm SEM: averaged 30-min values measured in the control period

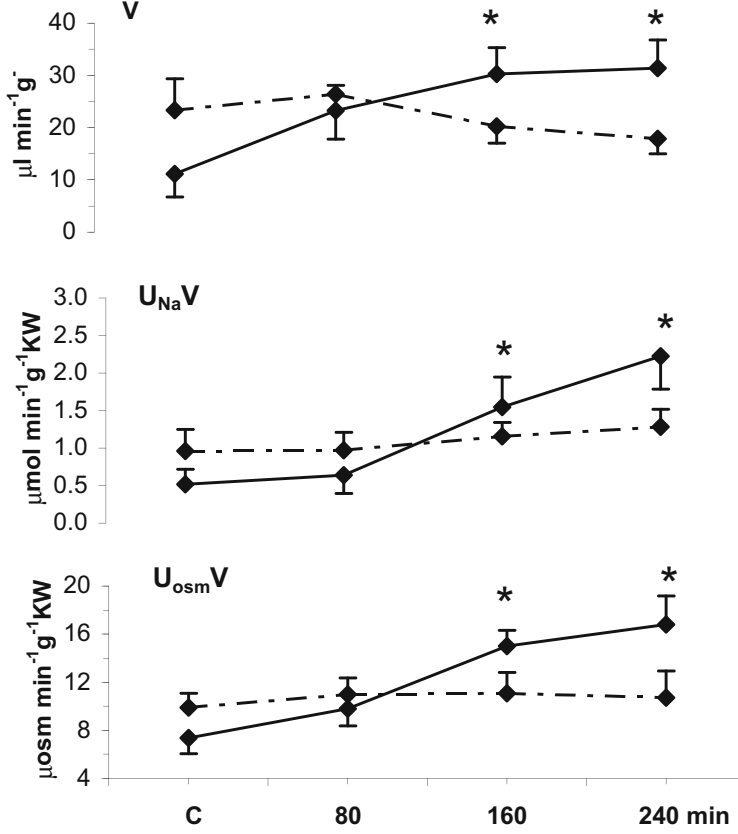

in the control period (C) and at the end of 80, 160 and $240 \mathrm{~min}$ of $\mathrm{Bk}$ infusion. Bk, continued line $(n=7)$; solvent, dotted line $(n=8)$. \#Significant difference between profiles at $P<0.001$ (repeated measurement ANOVA); *significantly different from pre-infusion control at $P<0.05$ or less (Duncan's post hoc test)

hours induce also systemic effects, e.g. vasodilation and a decrease in blood pressure.
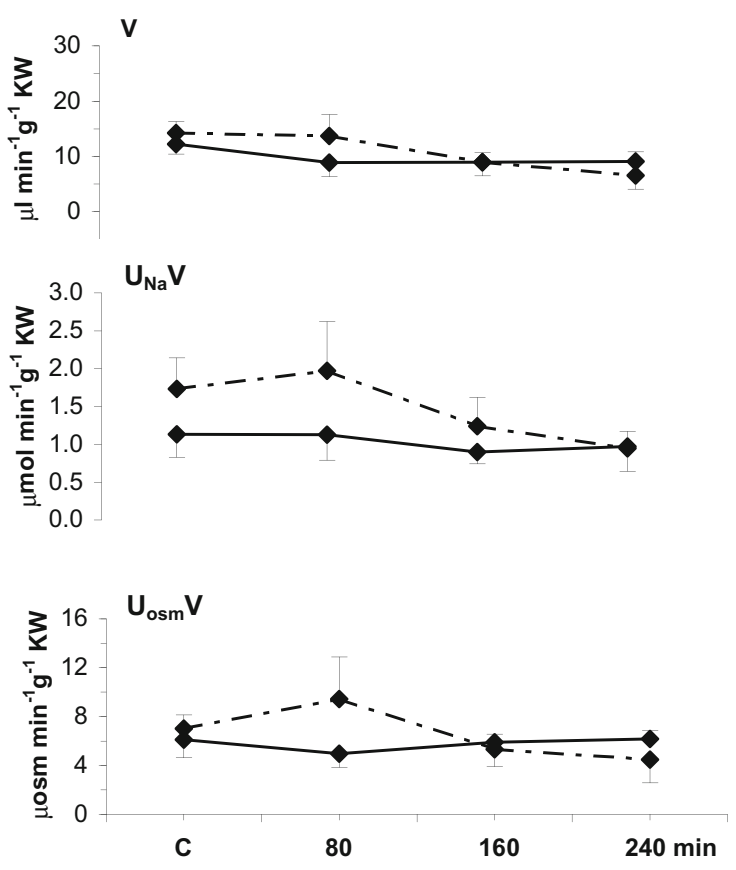

(C) and at the end of 80,160 and 240 min of Bk infusion. Bk, continued line $(n=7)$; solvent, dotted line $(n=7)$. \#Significant difference between profiles at $P<0.01$ (repeated measurement ANOVA); *significantly different from pre-infusion control at $P<0.02$ or less (Duncan's post hoc test) 
Table 3 A comparison of tissue osmolality and sodium concentration $[\mathrm{Na}+]$ in the inner medulla, measured at the end of Bk and solvent infusion studies in the three experimental groups

\begin{tabular}{|c|c|c|c|c|}
\hline & \multicolumn{2}{|c|}{ Medullary osmolality } & \multicolumn{2}{|c|}{ Medullary $\left[\mathrm{Na}^{+}\right]$} \\
\hline & \multicolumn{2}{|c|}{ (mosm $\mathrm{kg}^{-1}$ wet medullary tissue) } & \multicolumn{2}{|c|}{ (mmol kg${ }^{-1}$ wet medullary tissue) } \\
\hline & $\mathrm{Bk}$ & Solvent & $\mathrm{Bk}$ & Solvent \\
\hline S-D & $614 \pm 129(8)$ & $656 \pm 42(6)$ & $123 \pm 12 *(8)$ & $166 \pm 7(6)$ \\
\hline S-D+NE & $497 \pm 49(7)$ & $551 \pm 68(8)$ & $109 \pm 8(7)$ & $123 \pm 9(8)$ \\
\hline DOCA-salt & $598 \pm 71(9)$ & $673 \pm 88(8)$ & $137 \pm 21(8)$ & $149 \pm 6(6)$ \\
\hline
\end{tabular}

S-D, normotensive Sprague-Dawley rats; S-D+NE, norepinephrine-induced hypertension rats; DOCA-salt, hypertensive rats; Bk, bradykinin. Values are means $\pm \mathrm{SEM} ; \mathrm{n}$ values are given in brackets

*Significantly lower than in the corresponding solvent infusion study. $\mathrm{P}<0.05$, unpaired Student's $\mathrm{t}$ test)

The findings do not bear directly on the postulate that medullary hyperperfusion, when maintained over days, lowers blood pressure as a result of natriuresis and extracellular fluid volume contraction. Clearly, longer lasting exposure to medullary hyperperfusion would be needed to examine whether an MBF change is or is not responsible for correction of blood pressure increase mediated by the pressure-natriuresis mechanism, e.g. in response to temporary or prolonged excessive salt intake.

In the next step of this work, as baseline situation for the study of the effects of medullary hyperperfusion we have chosen a moderate elevation of arterial pressure secondary to acute infusion of NE; such a model might be thought to resemble a border-line hypertension of short duration. We hoped to obtain circumstances in which the dominating clearly defined alteration, i.e. BP elevation would be countered, or not, by increased perfusion of the medulla. Within a 4-h experiment, the known multiple long-term consequences of $\mathrm{NE}$ excess (e.g. sodium retention or stimulation of renin release) might not yet have come into play. Indeed, during experiment, there was no sodium or water retention: in fact, the excretion increased, most probably due to the dominating effect of pressure natriuresis (Fig. 3). Not likely within that short time period was also any major stimulation of renin release and activation of the renin-angiotensin system (RAS), especially an elevation of plasma angiotensin II (Ang II). If present, it would probably be associated with an increase in RVR greater than the observed $30 \%$ elevation. In our earlier study, we demonstrated that with the doses of the two vasodepressors matched to induce the same acute BP elevation, RVR increased $45 \%$ with NE and $130 \%$ with AngII, indicating specific renal vasoconstrictor action of the latter [12]. Overall, our S-D+NE group should be described as one with "temporary or transient pressure elevation" rather than established experimental hypertension.

We found that under conditions of such moderate blood pressure elevation a substantial (65\%) increase in MBF did not cause any decrease in arterial pressure, the result similar as observed with normal baseline BP level. Evidently, increased renal medullary perfusion was not a factor likely to cause a decrease in arterial pressure, similarly at normal and modestly elevated baseline pressure level. This finding is comparable with that of our previous study where we examined the response of arterial pressure to experimental renal medullary hyperperfusion in salt-loading hypertension, AngII-induced hypertension and in spontaneously hypertensive rats (SHR), a genetic model with fairly complex pathogenetic background [10]. It will be noticed that in the SD-NE rats (not in the two other models), the parameters of renal excretion increased during Bk-induced medullary hyperperfusion (Fig. 3), indicating some effect postulated by the renocentric theory. However, even though increasing, the excretion rates were lower than the total fluid infusion rate during the experiment so that the rats were retaining and not losing body fluid (positive balance). In conclusion, such minor and short-lasting natriuresis was wholly unlikely to have caused any significant ECF volume change which might affect blood pressure.

In the last step of the present work, we examined the response to renal medullary hyperperfusion in rat DOCA-salt hypertension, a model not explored in this respect in our earlier studies. The model consists primarily of sodium retention (related to increased sodium intake and inhibited tubular sodium reabsorption due to increased mineralocorticoid activity) and inhibition of renin release. However, the hypertension is also of neurogenic origin, apparently dependent on activation of the brain renin-angiotensin system (RAS) [4, 29] . Interestingly, DOCA-salt mice were reported to display diminished pressure-natriuresis, possibly dependent on abnormal response of MBF [20]. The DOCA-salt model can be thought to mimic, at least to some extent, the low-renin hypertension in humans.

In DOCA-salt hypertensive rats, a mean Bk-induced selective increase in MBF was substantial $(+70 \%)$ and within first $80 \mathrm{~min}$ was associated with a distinct decrease in MAP. 
However, the fall was quite similar as that seen with solvent infusion where the same MAP decrease also occurred. Hence, no pathogenetic role can be ascribed to this initial BP decrease. Later during experiment in Bk-infused rats, MAP remained stable, and in the solvent counterparts, it decreased further. Unexpectedly, the progressing MBF increase in the former appeared to oppose the decrease in MAP observed in time-control experiments. On the whole, there was not the least evidence on MBF-mediated decrease in arterial pressure.

An obvious limitation of this study is that experiments were conducted under anaesthesia. Very likely, this was responsible for the decrease in BP observed during DOCA-salt group experiments. The reason might be a progressing inhibition by the anaesthetic of the diverse pro-hypertensive mechanisms activated during prolonged sodium retention and hyperactivity of the sympathetic nervous system; such activation is an established feature of the DOCA-salt model. Notably, no such pressure decrease was observed here in normotensive rats or in the group with recent acute BP elevation (S-D+NE group), i.e. when the mentioned mechanisms have not yet been activated. However, interpretation of the different response pattern is difficult. In normotensive and NE-infused rats, the baseline sympathetic tone must have been elevated as a result of anaesthesia and extensive experimental surgery (including acute right-side nephrectomy) and in NE-infused rats subjected to the same procedures, the actual status of the brain and peripheral sympathetic nervous system would be difficult to predict and would require another focused study.

In that and the present study of rat hypertension models, the decrease in BP can by no means be ascribed to the medullary hyperperfusion since a similar or even greater reduction of $\mathrm{BP}$ was observed with intramedullary solvent and no change in MBF. It will also be noticed that in our earlier studies comparable negative results (increased MBF, wash-out of medullary $\mathrm{Na}^{+}$but no decrease in BP) were obtained in chronic (no anaesthesia) exposure of conscious rats to medullary vasodilator action of $\mathrm{Bk}[10]$.

In conclusion, the study provides new data indicating that a change in renal medullary perfusion is not a critical factor enabling correction of blood pressure fluctuations in normotensive animals or animals with modestly elevated blood pressure. Nor is it important in the pathogenesis of rat hypertension dependent on sodium retention associated with activation of the brain RAS, a model resembling in some respects the low-renin hypertension in humans. Together with earlier data, the rate of medullary perfusion is shown to have no role in control of arterial pressure in experiments with normotensive and hypertensive rats, at least when examined during the first 4-h period of MBF elevation.

Author contribution J. Sadowski and B. Bądzyńska provided the study conception and design. B. Bądzyńska performed all experiments. I.
Baranowska participated in the experiments and performed medullary tissue analysis. B. Bądzyńska and J. Sadowski evaluated the data and prepared the first draft of the manuscript. J. Sadowski wrote the final version of the manuscript.

Funding This research was supported in part by National Science Centre, Poland (Grant: 2014/15/B/NZ4/01100).

\section{Declarations}

Conflict of interest The authors declare that they have no conflict of interest.

Open Access This article is licensed under a Creative Commons Attribution 4.0 International License, which permits use, sharing, adaptation, distribution and reproduction in any medium or format, as long as you give appropriate credit to the original author(s) and the source, provide a link to the Creative Commons licence, and indicate if changes were made. The images or other third party material in this article are included in the article's Creative Commons licence, unless indicated otherwise in a credit line to the material. If material is not included in the article's Creative Commons licence and your intended use is not permitted by statutory regulation or exceeds the permitted use, you will need to obtain permission directly from the copyright holder. To view a copy of this licence, visit http://creativecommons.org/licenses/by/4.0/.

\section{References}

1. Assersen KB, Høilund-Carlsen PF, Olsen MH, Greve SV, GamHadberg JC, Braad P-E, Damkjaer M, Bie P (2019) The exaggerated natriuresis of essential hypertension occurs independently of changes in renal medullary blood flow. Acta Physiol (Oxford, England) 226:e13266. https://doi.org/10.1111/apha.13266

2. Averina VA, Othmer HG, Fink GD, Osborn JW (2012) A new conceptual paradigm for the haemodynamics of salt-sensitive hypertension: a mathematical modelling approach. J Physiol 590: 5975-5992

3. Azizi M, Schmieder RE, Mahfoud F, Weber MA, Daemen J, Davies J, Basile J, Kirtane AJ, Wang Y, Lobo MD, Saxena M, Feyz L, Rader F, Lurz P, Sayer J, Sapoval M, Levy T, Sanghvi K, Abraham J, Sharp ASP, Fisher NDL, Bloch MJ, Reeve-Stoffer H, Coleman L, Mullin C, Mauri L, Wang Y, Jay D, Skeik N, Schwartz R, Rader F, Dohad S, Victor R, Sanghvi K, Costello J, Walsh C, Abraham J, Owan T, Abraham A, Fisher NDL, Mauri L, Sobieszczky P, Williams J, Bloch MJ, Roongsritong C, Todoran T, Basile J, Powers E, Hodskins E, Fong P, Laffer C, Gainer J, Robbins M, Reilly JP, Cash M, Goldman J, Aggarwal S, Ledley G, Hsi D, Martin S, Portnay E, Calhoun D, McElderry T, Maddox W, Oparil S, Huang PH, Jose P, Khuddus M, Zentko S, O'Meara J, Barb I, Garasic J, Drachman D, Zusman R, Rosenfield K, Devireddy C, Lea J, Wells B, Stouffer R, Hinderliter A, Pauley E, Potluri S, Biedermann S, Bangalore S, Williams S, Zidar D, Shishehbor M, Effron B, Costa M, Kirtane AJ, Radhakrishnan J, Lobo MD, Saxena M, Mathur A, Jain A, Sayer J, Iyer SG, Robinson N, Edroos SA, Levy T, Patel A, Beckett D, Bent C, Davies J, Chapman N, Shun-Shin M, Howard J, Sharp ASP, Joseph A, D'Souza R, Gerber R, Faris M, Marshall AJ, Elorz C, Lurz P, Höllriegel R, Fengler K, Rommel KP, Mahfoud F, Böhm M, Ewen S, Lucic J, Schmieder RE, Ott C, Schmid A, Uder M, Rump LC, Stegbauer J, Kröpil P, Azizi M, Sapoval M, Cornu E, Fouassier D, Gosse P, Cremer A, Trillaud H, Papadopoulos P, 
Pathak A, Honton B, Lantelme P, Berge C, Courand PY, Daemen J, Feyz L, Blankestijn PJ, Voskuil M, Rittersma Z, Kroon AA, van Zwam WH, Persu A, Renkin J (2018) Endovascular ultrasound renal denervation to treat hypertension (RADIANCE-HTN SOLO): a multicentre, international, single-blind, randomised, sham-controlled trial. Lancet 391:2335-2345

4. Basting T, Lazartigues E (2017) DOCA-salt hypertension: an update. Curr Hypertens Rep 19:32, Secondary Hypertension: Nervous System Mechanisms. https://doi.org/10.10007/s11906-017-0731-42017

5. Beard DA, Feigl EO (2011) Understanding Guyton's venous return curves. Am J Physiol Heart Circ Physiol 301:H629-H633

6. Beard DA (2013) Tautology vs. physiology in the etiology of hypertension. Physiology (Bethesda) 28:270-271. https://doi.org/10. 1152/physiol.00038.2013

7. Bergström G, Evans RG (2004) Mechanism underlying the antihypertensive functions of the renal medulla. Acta Physiol Scand 181: 475-486

8. Bie P (2009) Blood volume, blood pressure and total body sodium: internal signalling and output control. Acta Physiol (Oxford, England) 195:187-196

9. Bie P, Evans RG (2017) Normotension, hypertension and body fluid regulation: brain and kidney. Acta Physiol (Oxford, England) 219:288-304. https://doi.org/10.1111/apha.12718

10. Bądzyńska B, Baranowska I, Gawryś O, Sadowski J (2019) Evidence against a crucial role of renal medullary perfusion in blood pressure control of hypertensive rats. J Physiol 597:211-223

11. Bądzyńska B, Sadowski J (2012) Experimental selective elevation of renal medullary blood flow in hypertensive rats: evidence against short-term hypotensive effect. Acta Physiol 205:484-493

12. Bądzyńska B, Sadowski J (2011) Moderate intrarenal vasoconstriction after high pressor doses of norepinephrine in the rat: comparison with effects of angiotensin II. Kidney Blood Pressure Res 34: 307-310. https://doi.org/10.1159/0003283282011

13. Cowley AW Jr (1992) Long-term control of arterial blood pressure. Physiol Rev 72:231-230

14. Cowley AW Jr, Mattson DL, Lu S, Roman RJ (1995) The renal medulla and hypertension. Hypertension 25:663-673. https://doi. org/10.1161/01.HYP.25.4.663

15. Cowley AW Jr (1997) The role of the renal medulla in volume and arterial pressure regulation. Am J Physiol Regul Integr Comp Physiol 273:R1-R15

16. Dobrowolski L, Sadowski J, Kompanowska-Jezierska E (1992) Conductance studies of rat renal medulla for rapid estimation of extracellular electrolyte concentration. Clin Phys Physiol Measur 13:257-262

17. Esler M, Lambert E, Schlaich M (2010) Point: chronic activation of the sympathetic nervous system is the dominant contributor to systemic hypertension. J Appl Physiol 109:1996-1998

18. Evans RG, Bie P (2016) Role of the kidney in the pathogenesis of hypertension: time for a neo-Guytonian paradigm or a paradigm shift? Am J Physiol Regul Integr Comp Physiol 310(3):R217R229. https://doi.org/10.1152/ajpregu.00254.2015

19. Evans RG, Head GA, Eppel GA, Burke SL, Rajapakse NW (2010) Neural, hormonal and renal interactions in long-term blood pressure control II. Angiotensin II and neurohumoral control of the renal medullary circulation. Clin Exp Pharmacol Physiol 37:e58-e69
20. Gross V, Lippoldt A, Bohlender J, Bader M, Hansson A, Luft FC (1998) Cortical and medullary hemodynamics in deoxycorticosterone acetate-salt hypertensive mice. Journal of the American Society of Nephrology 9:346-354

21. Guyenet PG (2006) The sympathetic control of blood pressure. Nat Rev Neurosci 7:335-346

22. Guyton AC (1961) Physiologic regulation of arterial pressure. Am J Cardiol 8:401-407

23. Guyton AC (1989) Dominant role of the kidneys and accessory role of whole-body autoregulation in the pathogenesis of hypertension. Am J Hypertens 2:575-585

24. Mancia G, Grassi G (2014) The autonomic nervous system and hypertension. Circ Res 114:1004-1021

25. Mattson DL (2003) Importance of the renal medullary circulation in the control of sodium excretion and blood pressure. Am J Physiol Regul Integr Comp Physiol 284:R13-R27

26. Muirhead EE (1990) Medullipin system of blood pressure control. News Physiol Sci 5:241-244

27. Osborn JW (2005) Hypothesis: set-points and long-term control of arterial pressure. A theoretical argument for a long-term arterial pressure control system in the brain rather than the kidney. Clin Exp Pharmacol Physiol 32:384-393

28. Sadowski J, Badzyńska B (2020) Altered renal medullary blood flow: a key factor or a parallel event in control of sodium excretion and blood pressure? Clin Exp Pharmacol Physiol. 47:1323-1332

29. Schenk J, McNeill JH (1992) The pathogenesis of DOCA-salt hypertension. J Pharmacol Toxicol Methods 27:161-170

30. Townsend RR, Mahfoud F, Kandzari DE, Kario K, Pocock S, Weber MA, Ewen S, Tsioufis K, Tousoulis D, Sharp ASP, Watkinson AF, Schmieder RE, Schmid A, Choi JW, East C, Walton A, Hopper I, Cohen DL, Wilensky R, Lee DP, Ma A, Devireddy CM, Lea JP, Lurz PC, Fengler K, Davies J, Chapman N, Cohen SA, DeBruin V, Fahy M, Jones DE, Rothman M, Böhm M, Aoki J, Batson B, Böhm M, Choi JW, Cohen DL, Dangas G, David S, Davies J, Devireddy CM, Kandzari D, Kario K, Lee DP, Lurz PC, Patel M, Patel K, Schmieder RE, Sharp ASP, Singh J, Tsioufis K, Walton A, Weber T, Weil J, Zeller T, Ziada K, Tanabe K, Wilkins R, Mahfoud F, East C, Wilensky R, Contreras J, Steigerwalt S, Chapman N, Lea JP, Reedus D, Hoshide S, Ma A, Fengler K, Svetkey L, Rao A, Schmid A, Watkinson AF, Brown A, Tousoulis D, Hopper I, Suppan M, Agdirlioglu T, Noory E, Chasen C (2017) Catheter-based renal denervation in patients with uncontrolled hypertension in the absence of antihypertensive medications (SPYRAL HTN-OFF MED): a randomised, sham-controlled, proof-of-concept trial. Lancet 390:2160-2170

31. Wallenstein S, Zucker CL, Fleiss JL (1980) Some statistical methods useful in circulation research. Circulation Res 47:1-9

32. Wang LY, Wang WK (2006) Point-counterpoint: The classical Guyton view that mean systemic pressure, right atrial pressure, and venous resistance govern venous return is/is not correct. $\mathrm{J}$ Appl Physiol 101:1528-1529

Publisher's note Springer Nature remains neutral with regard to jurisdictional claims in published maps and institutional affiliations. 